\title{
Manajemen Revitalisasi Sarana dan Prasarana Pendidikan dalam upaya Meningkatkan Efektivitas Pembelajaran Produktif di SMKN 13 Bandung
}

\author{
Donni Muhamad1, Heru Sujiarto ${ }^{2}$, Ade Tutty R. Rosa ${ }^{3}$
}

1,2,3 Universitas Islam Nusantara, Indonesia

E-mail: donnimuhamad@yahoo.com, hsujiarto@gmail.com, adetuttyrosa@uninus.ac.id

\begin{tabular}{|c|c|}
\hline Article Info & Abstract \\
\hline Article History & This study aims to describe, analyze and produce solutions regarding planning, \\
\hline Received: 2021-10-09 & zing, implementing and monitoring, obstacles, and efforts to overcome the use of \\
\hline Revised: 2021-11-02 & facilities and infrastructure in supporting effective learning at SMKN 13 Bandung. The \\
\hline $1-24$ & theory that underlies this research is the management theory proposed by George $\mathrm{R}$ \\
\hline & $\begin{array}{l}\text { Terry which includes Planning, Organizing, Actuating and Controlling. The research } \\
\text { procedure used is descriptive analytic approach, and data collection techniques }\end{array}$ \\
\hline & through interviews, observation and study documentation. The results of the study \\
\hline Facilities; & indicate that the revitalization of facilities and infrastructure in the analytical \\
\hline $\begin{array}{l}\text { Infrastructure; } \\
\text { Revitalization; }\end{array}$ & expertise competency has been carried out in accordance with the \\
\hline Pro & $\begin{array}{l}\text { visions and standards set, this can be seen from the seriousness of the school in } \\
\text { nning, organizing, implementing and supervising which leads to the effectiveness of }\end{array}$ \\
\hline
\end{tabular}

\begin{tabular}{l}
\hline Artikel Info \\
\hline Sejarah Artikel \\
Diterima: $2021-10-09$ \\
Direvisi: 2021-11-02 \\
Dipublikasi: 2021-11-24
\end{tabular}

\section{Abstrak}

Penelitian ini bertujuan untuk mendeskripsikan, menganalisis dan menghasilkan solusi tentang perencanaan, pengorganisasian, pelaksanaan dan pengawasan, kendala, serta upaya untuk mengatasi kendala pada pemanfaatan sarana dan prasarana dalam mendukung pembelajaran yang efektif di SMKN 13 Bandung. Teori yang melandasi penelitian ini adalah teori manajemen yang dikemukakan oleh George R Terry meliputi

Kata kunci:

Manajemen;

Sarana;

Prasarana:

Revitalisasi;

Pembelajaran Produktif. Planning (Perencanaan), Organizing (Pengorganisasian), Actuating (Pelaksanaan) dan Controlling (Pengawasan). Prosedur penelitian yang digunakan adalah deskriptif analitik dengan pendekatan kualitatif, dan teknik pengumpulan data melalui wawancara, observasi dan studi dokumentasi. Hasil penelitian menunjukkan bahwa revitalisasi sarana dan prasarana pada kompetensi keahlian Kimia Analisis telah dilaksanakan sesuai ketentuan dan standar yang ditetapkan, hal ini terlihat dari kesungguhan sekolah dalam perencanaan, pengorganisasian, pelaksanaan dan pengawasan yang mengarah pada efektivitas pembelajaran produktif dan peningkatan kompetensi siswa SMK.

\section{PENDAHULUAN}

Pelaksanaan pendidikan nasional harus menjamin meningkatkan mutu pendidikan ditengah perubahan, agar warga Indonesia menjadi manusia yang bertakwa kepada Tuhan Yang Maha Esa, berakhlak mulia, cerdas, produktif, dan berdaya saing tinggi dalam pergaulan nasional maupun internasional. Untuk menjamin tujuan pendidikan tersebut, pemerintah telah mengamanatkan delapan Standar Nasional Pendidikan sebagaimana diatur dalam Peraturan Pemerintah Republik Indonesia No. 13 Tahun 2015 Tentang Standar Nasional Pendidikan. Pendidikan merupakan suatu system yang saling mempengaruhi dan bergantung dalam mencapai tujuan pendidikan sesuai dengan apa yang diharapkan bersama, Pendidikan merupakan hal yang penting bagi kehidupan manusia. Pendidikan merupakan investasi yang paling utama bagi bangsa, apa lagi bangsa yang sedang berkembang. Pembangunan hanya dapat dilakukan oleh manusia yang dipersiapkan untuk itu melalui pendidikan, para pakar pendidikan mengatakan bahwa fungsi utama sekolah adalah pembinaan dan pengembangan semua potensi individu terutama pengembangan potensi fisik, intelektual dan moral setiap peserta didik. Maka sekolah harus dapat berfungsi sebagai tempat pendidikan formal untuk mengembangkan semua potensi peserta didik sebagai sumber daya manusia, Manusia membutuhkan pendidikan dalam kehidupannya. Pendidikan merupakan usaha sadar agar manusia dapat mengembangkan potensi dirinya melalui proses pembelajaran dengan cara lain yang dikenal dan diakui oleh masyarakat. Pendidikan merupakan sesuatu yang sangat urgent dalam kehidupan manusia. Dalam kenyataannya, pendidikan telah mampu membawa manusia kearah kehidupan yang lebih 
beradab. Pendidikan telah ada seiring dengan lahirnya manusia.

Badan Pusat Statistik (BPS) tahun 2019, merilis tingkat pengangguran terbuka (TPT) Indonesia yang masih didominasi oleh lulusan Sekolah Menengah Kejuruan (SMK) sebesar 8,63\%, disusul oleh Diploma (D3) 6,89\%. Pengangguran terbanyak berasal dari SMK dan D3. Faktor tingginya angka pengangguran lulusan Sekolah Menengah Kejuruan (SMK), ternyata disebabkan oleh banyak aspek, baik aspek supply (persediaan) maupun aspek demand (permintaan). Adanya kesenjangan kompetensi juga menyebabkan terjadinya ketidaksesuaian antara supply dan demand tenaga kerja. Adanya kesenjangan kompetensi merupakan akibat langsung salah satunya dari sarana atau alat-alat utama produktif yang digunakan di SMK tidak sesuai dan tertinggal dengan perkembangan DU/DI.

Selain itu ditemukan kecenderungan bahwa sarana dan prasarana pendidikan di sekolah SMK tidak dikelola dengan pengetahuan yang cukup sehingga sering terjadi ketidaktepatan dalam pengelolaan. Ketidaktepatan pengelolaan sarana dan prasarana pendidikan menyangkut data perencanaan sarana dan prasarana, penanggung jawab, pengelola sarana, meliputi cara pengadaan, pemeliharaan dan perawat, serta penghapusan, Penelitian ini bertujuan untuk mengetahui, mendeskripsikan, menganalisis tentang pelaksanaan manajemen revitalisasi sarana dan prasarana pada pembelajaran produktif di SMKN 13 Bandung yang meliputi proses perencanaan, pengawasan, hasil, kendala yang dihadapi dan upaya yang dapat dilakukan untuk mengatasi kendala sarana prasarana serta mengetahui tren pendidikan berupa Sekolah Pencetak Wirausaha (SPW) melalui program Bekerja Melanjutkan dan Wirausaha (BMW) sebagai bagian dari program revitalisasi SMK.

\section{METODE PENELITIAN}

Pendekatan kualitatif dalam penelitian ini digunakan untuk mendeskripsikan dan menganalisis fenomena lemahnya kompetensi siswa sebagai hasil dari proses pembelajaran. Pendekatan penelitian kualitatif dengan metode studi kasus digunakan dalam teknik penelitian ini, Tempat ataupun wilayah yang akan dijadikan lokasi dalam penelitian ini adalah SMK Negeri 13 Bandung Bandung, sedangkan Teknik pengumpulan data yang digunakan dalam penelitian ini mengguanakan metode observasi, wawancara dan studi dokumentasi.
Adapun pada tahap pengolahan data dikumpulkan data-data yang diperoleh ditulis dalam catatan-catatan lapangan secara terpisah untuk setiap metode. Data dalam penelitian ini bersifat naratif deskriptif kualitatif, maka analisa terhadap data yang diperoleh bersifat narasi kualitatif, dan Teknik analisis data yang digunakan dalam penelitian ini adalah deskriptif naratif model Miles and Huberman ( 2014 ), yang meliputi data collecting, data reduction, data display dan conclusion drawing/verification.

\section{HASIL DAN PEMBAHASAN}

Hasil dari penelitian ini menunjukan bahwa perencanaan dalam merevitalisasi sarana prasarana pada pembelajaran produktif di Laboratorium Kimia Analis SMKN 13 Bandung diantaranya yaitu perencanaan pengembangan revitalisasi bangunan gedung dan perencanaan pengembangan revitalisasi peralatan praktik. Adapun tahapan perencanaan yang dilakukan adalah melalui proses analisis kebutuhan, analisis biaya dan analisis prioritas dengan melibatkan aspek internal dan eksternal. Aspek internal meliputi guru, TU, manajemen dan komite. Adapun yang eksternalnya meliputi DU/DI yang memiliki program kerjasama dengan sekolah.

Pengorganisasian pengelola kegiatan revitalisasi sarana dan prasarana di SMK Negeri 13 Bandung, secara struktur tidak mengubah struktur yang ada, namun apabila ada kebutuhan personil untuk membantu bidang garapan sehubungan dengan adanya bantuan maka kepala sekolah membentuk tim teknis yang dibentuk secara khusus dan menerbitkan Surat Tugas yang bersifat temporer dan berlaku sepanjang kegiatan berlangsung. Dalam pengorganiasiannya memperhatikan Struktur organisasi, penempatan personal sesuai kompetensi dan tupoksi yang ada sesuai dengan tujuan yang telah ditetapkan, pada tahapan pelaksanaan sarana dan prasarana ini mencakup beberapa tahapan mulai dari pengadaan sarana prasarana, invetarisir, penyimpanan, pendistribusian sarana prasarana dan penggunaan sarana prasarana pendidikan di sekolah, pengawasan atau kontrol terhadap sarana dan prasarana yang ada di sekolah dilakukan melalui perawatan/ pemeliharaan sarana dan prasarana pendidikan dan penghapusan sarana dan prasarana pendidikan.

Hasil revitalisasi sarana dan prasarana di Sekolah Menengah Kejuruan dalam upaya meningkatkan efektivitas pembelajaran produktif di SMKN 13 Bandung, menunjukkan 
peningkatan dan perbaikan dalam berbagai komponen, yaitu : pertama, adanya penambahan bangunan gedung Laboratorium Kimia sebanyak 2 bangunan gedung berupa Ruang Praktik Siswa yakni Laboratorium Kimia Instrumen dengan ukuran yang luas (198 $\mathrm{m} 2$ ) dan representatif dan sudah dilengkapai dengan peralatan modern kemudian Laboratorium Mokrobiologi (185 m2) merupakan pengembangan Ruang Laboratorium Kimia Dasar. Kedua, adanya peralatan instrumen yang sesuai dengan peralatan praktik yang digunakan di DU/DI seperti AAS Spektrofotometer UV Vis, Gas Chromatografhy, Hight performance Liquid Chromatografhy, Refraktometer dan lain-lain, Ketiga, hasil dari bantuan revitalisasi berdampak terhadap pembelajaran yang semakin fokus, kondusif dan nyaman.

Kendala dalam perencanaan pemenuhan sarana dan prasarana pembelajaran di sekolah adalah dalam perhitungan analisisis kebutuhan sarana dan prasarana terkendala dengan prediksi besaran harga satuan, sehingga menyebabkan terjadi perubahan quantity barang menjadi berkurang pada saat pengadaan karena harga tidak cocok atau akibat lainnya, jika quantity yang di pertahankan, maka quality barang yang dibeli akan menurun dikarenakan perubahan level spesifikasi barang yang menurun. (menurun kualitasnya), kendala lain adalah dalam pengadaan sarana dan prasarana pendidikan di sekolah adalah ketika ada pembangunan menjadikan sebagian ruang kelas terganggu sehingga sebagian kelas tidak bisa digunakan, kemudian dalam hal pengunaan alat instrument modern hasil bantuan sebagian guru tidak bisa menggunakan alat tersebut, sehingga kurang efektif dalam sisi pemanfaatan.

Kendala berikutnya adalah inventarisir dan penghapusan sarana dan prasarana pendidikan di sekolah. Kurang berjalannya proses inventarisir sarana dan prasarana mengakibatkan kondisi barang menjadi tidak bisa digunakan. Dokumen inventaris hampir setiap barang yang diinput sebagai asset tapi pada Kartu Inventaris Ruang (KIR), jika harga asset tersebut tidak tercantum, ini menjadi masalah jika ada penilaian asset yang dimiliki sekolah menjadi tdk diketahui nilai kekayaan yang dimiliki sekolah.

Upaya yang dapat dilakukan untuk mengatasi kendala dalam perencanaan adalah dengan memebuat perhitungan analisisis kebutuhan sarana dan prasarana yang lebih rinci dan sesuai dengan kebutuhan, sehingga dengan demikian maka dihasilkan analisis kebutuhan yang sesuai dari tinjuan jumlah, spesifikasi dan kualitas barang yang akan dibeli.

Upaya yang dapat dilakukan untuk mengatasi kendala dalam penggunaan sarana dan prasarana pendidikan berupa ruang belajar di sekolah, adalah kepala sekolah menginstruksikan wakasek bidang sarana prasarana dan wakasek bidang kurikulum untuk membuat rekayasa jadwal penggunaan ruang belajar, kemudian untuk mengatasi kendala dalam penggunaan peralatan praktik instrumen, sekolah mengambil langkah dengan mengadakan peningkatan kompetensi guru dalam meng-operasikan alat tersebut dengan melibatkan pihak eksternal melalui Memorandum Of Understanding (MOU).

Upaya untuk mengatasi kendala dalam inventarisir barang adalah dengan menunjuk pengurus barang untuk mengikuti peningkatan kompetensi melalui diklat atau workshop dan melakukan langkah-langkah berupa pengecekan kembali barang atau peralatan sekolah, trend pendidikan dalam program BMW (Belajar, Melanjutkan, Wirausaha) sebagai bagian dari program revitalisasi SMK di Sekolah Menengah Kejuruan (SMK) Negeri 13 Bandung adalah kewirausahaan. Langkah-langkah yang dilakukan sekolah meningkatkan program wirausaha ini adalah mengadakan penguatan kurikulum melalui program SPW (Sekolah Pencetak Wirausaha) yang merupakan model pembelajaran yang mendorong siswa untuk memiliki keterampilan melalui praktik usaha, salah satu contoh kegiatan wirausaha yang dilaksanakan pada kompetensi keahlian kimia analisis adalah pada kegiatan praktikum kimia membuat sabun. Hasil praktikum di sekolah dan kegiatan yang dilakukan di rumah untuk produk yang sejenis dijadikan sebagai bagian kegiatan wirausaha dengan menjual produk tersebut.

\section{SIMPULAN DAN SARAN}

\section{A. Simpulan}

Revitalisasi sarana dan prasarana pendidikan dalam upaya meningkatkan efektivitas pembelajaran produktif di SMK Negeri 13 Bandung telah dilaksanakan sesuai dengan ketentuan. Hal tersebut dapat terlihat dari kesungguhan sekolah dalam perencanaan, pengorganisasian, pelaksanaan dan pengawasan sarana dan prasraan yang mengarah kepada peningkatan efektivitas pembelajaran di Laboratorium kimia analisis Kepala SMK Negeri 13 Bandung, Trend pendidikan dalam program BMW sebagai bagian dari program revitalisasi SMK di Sekolah Menengah 
Kejuruan (SMK) Negeri 13 Bandung adalah kewirausahaan.

\section{B. Saran}

Rekomendasi atau saran yang dapat penulis kemukakan yaitu:

1. Kepada Kepala Sekolah selaku pimpinan yang professional berperan sebagai manajer dalam pengelolaan pendidikan di sekolah agar lebih optimal dalam mengelola sarana dan prasarana agar proses pembelajaran berlangsung efektif dan dapat mendorong peningkatan kompetensi siswa.

2. Kepada Guru bahwa perlu dilakukan upaya peningkatan kompetensi guru-guru produktif.

3. Kepada pengurus barang yaitu sebagai petugas pengelola sarana agar mengikuti peningkatan kompetensi secara terus menerus.

4. Kepada Peneliti untuk dapat memperbaiki kualitas pembelajaran produktif dan dapat memberikan masukan kepada segenap guru kompetensi keahlian.

5. Kepada peneliti selanjutnya yang tertarik dengan permasalahan yang penulis teliti, diharapkan mendapatkan informasi awal dalam mengembangkan dan memperluas kajian terkait revitalisasi sarana dan prasarana di sekolah.

\section{DAFTAR RUJUKAN}

AB Susanto, 2007, A Strategic Management Approach, CSR, The Jakarta.

Al-Qur'an dan terjemahannya. 2008. Departemen Agama RI. Bandung: Diponegoro.

Bafadal, Ibrahim. 2004. Manajemen Perlengkapan Sekolah Teori dan. Aplikasinya. Jakarta: Bumi Aksara.

Barnawi \& M. Arifin. 2012 Manajemen Sarana dan Prasarana sekolah. Jogyakarta: Ar-Ruzz Media.

Belmo, Karolus. 2012. Manajemen Sarana dan Prasarana Pada Sekolah Menengah Kejuruan (Studi Multi Situs di SMK Negeri 2 Belu dan SMK Negeri Kakuluk Mesak). Tesis, Program Studi Manajemen Pendidikan, Program Pascasarjana Universitas Negeri Malang. (online).

(http://repository.um.ac.id/57467/, diakses tanggal 14 Juli 2021, pukul 16.38 WIB)

Departemen Pendidikan Nasional. (2003). Undang-undang No. 20 tahun 2003 tentang Sistem Pendidikan Nasional. Jakarta: Depdiknas.

Depdiknas (2008). Kurikulum Tingkat Satuan Pendidikan. Jakarta : Dikmenum

Depdiknas, (2007). Kamus Besar Bahasa Indonesia.

Depdiknas. (2009). Pengembangan Rencana Pelaksanaan Pembelajaran. Jakarta: Depdiknas

Fattah, Nanang, 2008, Landasan Manajemen Pendidikan, Bandung: PT Remaja. Rosdakarya.

George R. Terry, 2006, Prinsip-Prinsip Manajemen. Jakarta: Penerbit Bumi. Aksara

Gonzales, N.C., Kuuskropi, M., Kaarina., \& Finland. 2011. The Future of The Phisical Learning Environment: School Facilities That Support The User. CELE Exchange. ISSN 2072-7925.

Gunawan, Imam dan Djum Djum Noor Benty. 2017. Manajemen Pendidikan, Suatu Pengantar Praktik, Bandung: Alfabeta

Inpres Nomor 9 tahun 2016 tentang Revitalisasi $S M K$

Komara, Sinsin Y. (2012). Rekrutmen dan Seleksi Tenaga Administrasi Sekolah Dasar Negeri di Kecamatan Sukasari Kota Bandung. Skripsi Sarjana pada FIP UPI Bandung: Tidak diterbitkan.

Kurniasih dan Sani. 2015. Model Pembelajaran. Yogyakarta: Kata Pena

Miles,M.B, Huberman,A.M, dan Saldana,J. 2014. Qualitative Data Analysis, A Methods Sourcebook, Edition 3. USA: Sage Publications. Terjemahan Tjetjep Rohindi Rohidi, UI-Press.

Mohamad, Mustari. 2014. Manajemen Pendidikan. Jakarta: Raja Grafindo. Persada. 
Peraturan Pemerintah Nomor 32 Tahun 2013 Tentang Perubahan atas Peraturan Pemerintah Nomor 19 Tahun 2005 Tentang Standar Nasional Pendidikan.

Permendikbud No.34 tahun 2018 tentang Standar Nasional Pendidikan (SNP) Sekolah Menengah Kejuruan/Madrasah Aliyah Kejuruan

Reza Ferdian, 2016. "Manajemen Sarana dan Prasarana Pendidikan pada SMK Farmasi ISFI dan SMK Farmasi Pondok Pesantren AlFurqan Banjarmasin". Tesis. Program Pascasarjana IAIN Antasari Banjarmasin. (online). (https://idr.uinantasari.ac.id/6830/, diakses tanggal 14 Juli 2021, pukul 16.25 WIB)

Sanusi, Ahmad. 2017. Sistem Nilai Alternatif Wajah-wajah Pendidikan. Bandung: Nuansa Cendikia.

Siagian, Sondang P, 2009, Manajemen Sumber Daya Manusia, Edisi.1, Cetakan.17 Jakarta, Bumi Aksara,
Sukardi, Thomas. 2008. Pengembangan Model Bengkel Kerja Praktik Sekolah Menengah Kejuruan. Desertasi Program Doktor. Tidak diterbitkan, Yogyakarta: Pasca Sarjana Universitas NEgeri Yogyakarta.

Susanta SA., Eddy \& Deni Koswara (2005). "Pengawasan dan Penilaian Satuan Pendidikan", dalam Deni Koswara \& Cepi Triatna (ed). Pengelolaan Pendidikan. Bandung: Jurusan Administrasi Pendidikan UPI.

Syafaruddin dan Irwan Nasution. (2005). Manajemen Pembelajaran. Jakarta: Quantum Teaching

Vygotsky. 1962. Teori Perkembangan Kognitif Vygotsky. Jakarta : Gramedia

Werang, Basilius Redan. 2015. Pendekatan Kuantitatif dalam Penelitian Sosial. Yogyakarta : Calpulis.

Wicaksono, Imam.2008. "Strategi Pembelajaran Matematika di SLTP Alternatif Qoryah Thoyyibah Kalibening Salatiga". Surakarta: Skripsi FKIP UMS (tidak diterbitkan) 